\title{
ROLE OF FINE NEEDLE ASPIRATION CYTOLOGY OF TESTES IN AZOOSPERMIA- A PROSPECTIVE OBSERVATIONAL STUDY
}

\author{
Vetrichandar $S^{1}$, Balaji A. $R^{2}$
}

${ }_{1}^{1}$ Senior Assistant Professor, Department of Urology, Stanley Medical College, Chennai, Tamilnadu, India.

2Professor and HOD, Department of Urology, Stanley Medical College, Chennai, Tamilnadu, India.

ABSTRACT
BACKGROUND
Male infertility is a common problem 1,2 that can be devastating for a couple to conceive. Studies reveal that $15 \%, 1-4$ of all future
marriages face the problem of infertility. The WHO has reported a global prevalence of $5 \%$ infertility in the mid $70 \mathrm{~s}$ in a
multicentric epidemiological study on infertility in various ${ }^{[1],[2]}$ countries including India. In approximately $30 \%$ of cases,
significant abnormalities are found in the man alone. In another $20 \%$ of the cases, abnormalities are found in both men and
women. Thus, in roughly $50 \%$ of infertile couples, the male factor is partially responsible for the infertility.

\section{MATERIALS AND METHODS}

A study of semen analysis- FNAC testis and testicular biopsy was done in 43 azoospermic males. The objectives of the study were to evaluate the features of testicular FNAC at cellular level (cytologically) in azoospermic males and to study the correlation between cytological and histological diagnosis. The need for bilateral FNAC was also evaluated. In FNAC, the most common diagnosis was maturation arrest (47\%). For evaluating the spermatogenic activity in male infertility, it appears that a unilateral FNAC or biopsy is sufficient for diagnosis.

\section{RESULTS}

Histopathology is considered as the gold standard for correct diagnosis. The correlation of FNAC with histopathology was $86 \%$ (pvalue 0.81 ). Our study showed an overall sensitivity of $88.6 \%$, specificity of $95.3 \%$, positive predictive value of $92.5 \%$ and negative predictive value of $94.4 \%$. No major complications were encountered during the procedure. Similarly, there was also good correlation (86\%) between the FNAC reports of left and right testes. This emphasises the fact that unilateral FNAC is more sufficient than for the evaluation of FNAC.

\section{CONCLUSION}

- Male infertility is a common problem ${ }^{1,2}$ that can be devastating for a couple to conceive.

- For evaluating the spermatogenic activity in male infertility, it appears that a unilateral FNAC or biopsy is sufficient for diagnosis.

- Bilateral FNACs and biopsies can be restricted to patients in whom there is appreciable difference in testicular size or consistency.

\section{KEY WORDS}

Fine Needle Aspiration Cytology, Azoospermia, Infertility.

HOW TO CITE THIS ARTICLE: Vetrichandar S, Balaji AR. Role of fine needle aspiration cytology of testes in azoospermia- a prospective observational study. J. Evolution Med. Dent. Sci. 2018;7(21):2617-2620, DOI: 10.14260/jemds/2018/588

\section{BACKGROUND}

In the assessment of male infertility, semen analysis is the most accepted initial investigation for evaluation of testicular function. Azoospermia is present in $10 \%-15 \%$ of men evaluated for infertility. Until recently testicular biopsy was the standard method for ascertaining the aetiology of azoospermia.[2] However, it requires a surgical procedure that is usually performed under general anaesthesia. As an alternative, testicular fine needle aspiration (FNA) has gained increasing popularity as a simple, minimally invasive and

'Financial or Other Competing Interest': None.

Submission 07-04-2018, Peer Review 05-05-2018,

Acceptance 11-05-2018, Published 21-05-2018.

Corresponding Author:

Vetrichandar $S$

1G6, DABC, Mithilam,

Sriram Nagar Main Road,

Nolambur, Chennai-95,

Tamilnadu, India

E-mail:drsvchandar@gmail.com

DOI: $10.14260 /$ jemds $/ 2018 / 588$

(c) (i) $९$ rapid technique that can be performed on an outpatient basis and also that can help in assessing testicular function accurately. Aspiration of testis was advocated in the initial decades of 19th century.[3]

Male infertility is a common problem that can be devastating to a couple trying to conceive. Studies reveal that $15 \%$ of all future marriages faces the problem of infertility.

Biopsy of the testis helps in differentiating a posttesticular obstructive aetiology of male infertility[4] from an intrinsic testicular cause. When post-testicular azoospermia or severe oligospermia is demonstrated, surgical correction may be indicated. ${ }^{[2,5]}$

Fine needle aspiration cytology (FNAC) of the testis is used as a minimally invasive method. Evaluating function of an upcoming alternative to open testicular biopsy is the fine needle aspiration cytology.[4,6]

(FNAC) is the method for obtaining material for cytological evaluation of spermatogenesis and interstitial cells.

We have studied the necessity of bilateral or unilateral FNACs in the workup of the infertile man. We have done this study to evaluate the efficacy of fine needle aspiration 
cytology (FNAC) as compared to open testicular biopsy in the evaluation of male infertility.

\section{Aims}

- To evaluate the possibility of replacing biopsy of azoospermia testes by FNAC for diagnostic purpose.

\section{Objectives}

- To evaluate the need for unilateral FNAC of the testes in the workup of the azoospermia.

- To evaluate cytological features of testicular FNAC in patients with azoospermia.

- To study the correlation between cytological and histological diagnosis.

- To determine the reliability of testicular FNAC as a cytological sampling technique in azoospermia.

\section{Study Design}

Prospective observational study.

\section{Setting}

Govt. Stanley Medical Hospital, Chennai.

\section{Period of Study}

January 2016 to January 2018.

The results were statistically analysed and calculated using Fisher's Exact Test.

\section{Inclusion Criteria}

Infertile men with two consecutive semen samples showing azoospermia done at least two weeks apart.

\section{Exclusion Criteria}

- Infertile men with only a single sample showing azoospermia.

- Infertile men with normal sperm counts or oligospermia.

- Infertile men with azoospermia in whom testicular biopsy/ FNAC is contraindicated due to causes like bleeding diathesis, infection etc.

A total of 43 were enrolled in the study after getting a proper informed consent.

\section{MATERIALS AND METHODS}

All infertile men with two successive samples showing azoospermia attending the Urology OPD from January 2016 to January 2018 in Stanley Hospital are included in the study. The patients are investigated with hormonal assays, scrotal USG in addition to routine investigation. The histopathology were considered as the gold standard when there is a discordance between the FNAC reports of both testes, the result which correlates with HPE was considered for statistical analysis.

A clinical examination was then conducted and relevant personal and clinical data were noted. Patients were then subjected to a fine needle aspiration of the testes for cytological evaluation. A specimen for histopathological correlation was obtained by open testicular biopsy. The procedures of the fine needle aspiration of the testes were done in the surgical outpatient department of the Stanley Medical College and Hospital, Chennai. With the patient in the supine position, the skin of the scrotum was prepared with $5 \%$ betadine solution. $5 \mathrm{~mL}$ of $1 \%$ xylocaine was injected into the spermatic cord bilaterally. Aspiration was done with a 22gauge needle attached to a $20 \mathrm{~mL}$ disposable syringe. The syringe was fixed on to a syringe holder. The needle was introduced in different directions to ensure that different areas were aspirated. Two such aspirates from each testis were taken. Air-dried and alcohol-fixed smears were prepared from the aspiration obtained and then subsequently stained with May-Grunwald-Giemsa (MGG) and haematoxylin and eosin ( $\mathrm{H}$ and $\mathrm{E}$ ) stains respectively. Histopathology was considered as the gold standard when there is a discordance between the FNAC reports of both testes, the result which correlates with HPE was considered for statistical analysis.

The results were statistically analysed and calculated using Fisher's Exact Test.

\section{RESULTS}

The mean age in our study was 32.3 years with a range of 25 to 42 years.

\section{Duration and the Type of Infertility}

Majority of patients presented 1 - 5 years after marriage with a mean duration of 5.84 years.

\section{History}

The majority of patients did not have any significant history (70\%).

\begin{tabular}{|c|c|}
\hline History & Present Study \\
\hline Nil significant & $70 \%$ \\
\hline Mumps orchitis & $13 \%$ \\
\hline Inguinal/ scrotal surgery & $16.2 \%$ \\
\hline \multicolumn{2}{|c|}{ Table 1. History of Risk Factor for Infertility } \\
\hline
\end{tabular}

This is comparable to study done by Khaled Madbouly et al. The majority of patients presented without any antecedent cause for infertility in both studies. Mumps orchitis was seen in only $2 \%$ of subjects in Khaled et al, unlike ours where it was seen in $13 \%$.

\section{Hormone Levels}

The mean testosterone, FSH and $\mathrm{LH}$ values in the present study were $6.2 \mathrm{ng} / \mathrm{mL}, 7.64 \mathrm{mIU} / \mathrm{L}, 6.48 \mathrm{mIU} / \mathrm{L}$ respectively.

\begin{tabular}{|c|c|}
\hline Hormone Levels & Present Study \\
\hline Testosterone & 6.2 \\
\hline FSH & 7.64 \\
\hline LH & 6.48 \\
\hline Table 2. Mean Hormone Levels in Study Population \\
\hline
\end{tabular}

\section{Testicular Size and Varicocele}

\begin{tabular}{|c|c|}
\hline Physical Examination & Present Study \\
\hline Normal sized testes & $78 \%$ \\
\hline Unilateral varicocele & $13 \%$ \\
\hline Bilateral varicocele & $8.6 \%$ \\
\hline Table 3. Frequency distribution of Testicular Size and \\
Varicocele \\
\hline
\end{tabular}




\section{FNAC- Cytological Types}

The most common cytological type was maturation arrest (47\%).

\begin{tabular}{|c|c|c|c|c|c|}
\hline 总 & 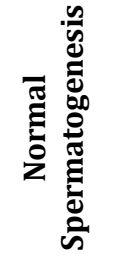 & 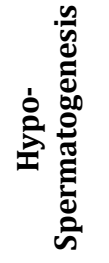 & 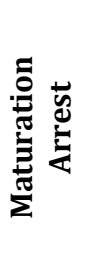 & 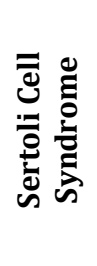 & 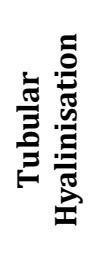 \\
\hline $\begin{array}{c}\text { Pres } \\
\text { ent } \\
\text { stud } \\
y\end{array}$ & $11.60 \%$ & $9.30 \%$ & $47 \%$ & $9.35 \%$ & $9.35 \%$ \\
\hline
\end{tabular}

The concordance rate between cytological findings of right and left testes was $86 \%$ in this study.

Correlation between FNAC of Right and Left testes- These findings suggest that in a patient undergoing testicular FNAC for azoospermia, the findings between right and left testis were comparable. Hence, it may be more than sufficient to limit the FNAC to just one testes.

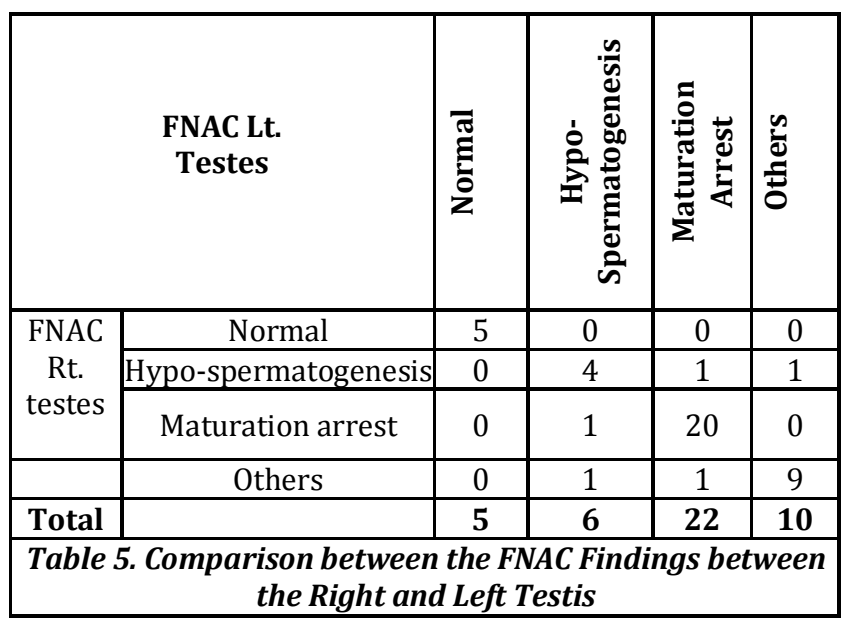

\section{Correlation between Testicular FNAC and} Histopathology

The correlation between FNAC and histopathology in our study was $88 \%$.

\begin{tabular}{|c|c|c|c|c|c|c|}
\hline $\begin{array}{l}\text { के } \\
\text { के } \\
\text { के }\end{array}$ & & 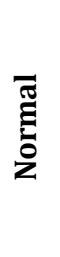 & & 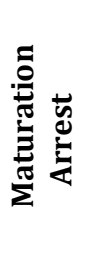 & 先 & 芜 \\
\hline \multirow{4}{*}{$\begin{array}{c}\text { FNAC } \\
\text { Left } \\
\text { Testes }\end{array}$} & Normal & 5 & 0 & 0 & 0 & 5 \\
\hline & $\begin{array}{c}\text { Hypo- } \\
\text { spermatogenesis }\end{array}$ & 1 & 4 & 1 & 0 & 6 \\
\hline & Maturation arrest & 0 & 3 & 19 & 0 & 22 \\
\hline & \begin{tabular}{|l|} 
Others \\
\end{tabular} & 0 & 2 & 0 & 8 & 10 \\
\hline Total & & 6 & 9 & 20 & 8 & 43 \\
\hline \multicolumn{7}{|c|}{$\begin{array}{l}\begin{array}{l}\text { Table 6. Comparison of Testicular Biopsy with FNAC of Lt. } \\
\text { Testes }\end{array} \\
\end{array}$} \\
\hline
\end{tabular}

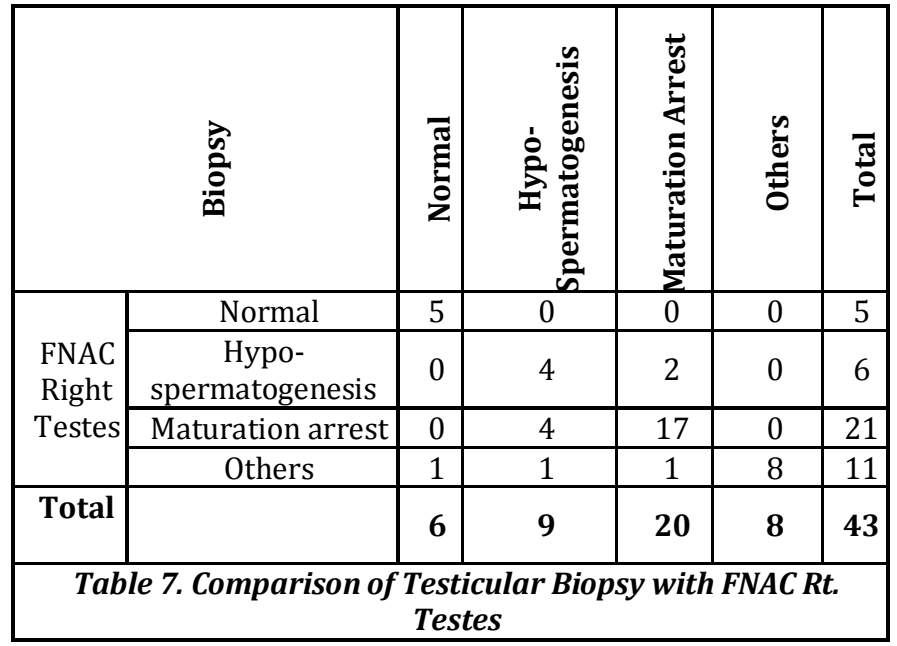

The above table show that there is good correlation between FNAC findings of both testes taken separately and the histopathological reports.

The difference between FNAC of right testes and HPE was not significant ( $\mathrm{P}$ value of $<0.463$ ).

The same was also noted for FNAC of the left testes. ${ }^{10}$ (P value $<0.281$ ).

\section{Correlation between Sperm Count and HPE}

In this there was $65.2 \%$ correlation between HPE diagnosis and sperm count.

\begin{tabular}{|c|c|}
\hline \multicolumn{2}{|c|}{ Present Study } \\
\hline $\begin{array}{l}\text { No. of } \\
\text { Cases }\end{array}$ & Percentage \\
\hline 28 & $65.2 \%$ \\
\hline \multicolumn{2}{|c|}{ Table 8. Correlation between Sperm Count and HPE } \\
\hline
\end{tabular}

\section{RESULTS}

The mean age of these patients was 32.3 years with a range of 25 to 42 years. All cases were primary infertility. Bilateral varicocele was observed in $8.6 \%$ of cases and unilateral varicocele in $13 \%$ of cases. Bilateral aspiration was done in all cases. Out of 43 patients, normal spermatogenesis in both testes was found in $05(11.6 \%)$ cases, hypo-spermatogenesis in both testes was found in $04(9.3 \%)$ cases. Sertoli cell syndrome and maturation arrest were found in $9.3 \%$ and $47 \%$ cases respectively. Sperm count, and histopathology results were correlated in $65 \%$ of cases.

\section{DISCUSSION}

Assessment of spermatogenesis is an important component in the diagnostic algorithm of male infertility. Traditionally, the surgical testis biopsy has been the gold standard in this evaluation, because it provides information in cases of both suspected obstruction and in failing on obstructed testes. Any technique to assess spermatogenesis must minimally invasive and must conserve as much testicular tissue as possible. It should also not only provide qualitative, but quantitative information about spermatogenesis.

Male factors are responsible for about half of all infertility cases. Until recently, testicular biopsy was the standard method to ascertain the aetiology of azoospermia. Posner and Huhner first used testicular puncture biopsies in the investigation of human infertility that examined unstained samples for spermatozoa.[7] Fine needle aspiration cytology 
has gained increasing popularity as a simple and minimally invasive procedure that can help in assessing testicular function accurately.

A preliminary testicular biopsy of both testes showed diffuse tubular atrophy with a stop of the spermatogenesis.[8] In addition to answering the question whether sperm production is normal, it must also address whether sperm are present at all within the testis, as with advances in field of reproductive medicine even a single sperm can now give men with NOA chance to enjoy biological fatherhood. Fine needle aspiration of the testis pioneered by Obrant and Persson (1965) was proposed as a non-invasive technique. Characterising the cell types in cytological smears was straight-forward with not much difficulty in recognising germ cells and sertoli cells.[9]

The minimum full evaluation for male infertility for every patient should include a complete medical history, physical examination by a urologist or other specialist in male reproduction and at least two semen analyses.[10] FNAC of the testis and scrotum is a simple, quick, minimally invasive and painless procedure. The sample obtained in outpatient department can be more representative than biopsy as several separate punctures can be made, and there is no local scarring. Semen analysis does not consistently provide definitive and predictive value in the assessment of male fertility potential. But despite its limitations it is simple, inexpensive and most important screening test with which to begin the laboratory evaluation of male infertility.[11]

There is a good correlation between histology of the testis and FNAC, resulting in latter gaining more popularity. ${ }^{[12]}$ The heterogeneity of the spermatogenetic process within the testis as well as between two testes requires sampling of both testes and multiple punctures. Single aspirate may not be truly representative.[13] However, some studies have described sampling of only one testis.[14] The study used sampling of both testes and findings are also different in both testes. In our study normal spermatogenesis was found in total $13.95 \%$ cases, hypospermatogenesis in $20.93 \%$ cases. These findings correlates with the finding of Adhikary RC, Rajwanshi A et al and Qublan HS et al.[14,15] However, we found maturation arrest in $47 \%$ cases and sertoli cell syndrome in $9.35 \%$ cases.

\section{CONCLUSION}

- The technique of testicular FNAC is simple, minimally traumatic and inexpensive. If the specimen is inadequate, repeat sample can be taken safely.

- Testicular FNAC gives an accuracy of $92.8 \%$ in the diagnosis of patients with male infertility.

- The material aspirated by FNAC is adequate and the various cell types can be identified by their distinctive morphology.

- This study proves that FNAC can evaluate accurately all classically defined histologic types.

- The accuracy of diagnosing normal spermatogenic activity in obstructive azoospermia by FNAC was $100 \%$.

- For evaluating the spermatogenic activity in male infertility, it appears that a unilateral FNAC or biopsy is sufficient for diagnosis.
- Bilateral FNACs and biopsies can be restricted to patients in whom there is appreciable difference in testicular size or consistency.

\section{REFERENCES}

[1] World Health Organization. The epidemiology of infertility. WHO Tech Rep Ser No 582, 1975: p. 5.

[2] Jarow JP, Espeland MA, Lipshultz LI. Evaluation of the azoospermic patient. J Urol 1989;142(1):62-5.

[3] World Health Organization. WHO laboratory manual for the examination of human semen and spermcervical mucus interaction. $4^{\text {th }}$ edn. Cambridge: Cambridge University Press 1999.

[4] Meng MV, Cha I, Ljung BM, et al. Testicular fine-needle aspiration in infertile men: correlation of cytologic pattern with biopsy histology. Am J Surg Pathol 2001;25(1):71-9.

[5] Altay B, Hekimgil M, Cikili N, et al. Histopathological mapping of open testicular biopsies in patients with unobstructive azoospermia. BJU Int 2001;87(9):8347.

[6] Dada R, Gupta NP, Kucheria K. Molecular screening for Yq micro deletion in men with idiopathic oligozoospermia and azoospermia. J Biosci 2003;28(2):163-8.

[7] Huhner M. Aspirations of the testicle in the diagnosis and prognosis of sterility. J Urol 1928;19(1):31-42.

[8] Zech H, Vanderzwalmen P, Prapas Y, et al. Congenital malformations after intra cytoplasmic injection of spermatids. Hum Reprod 2000;15(4):969-71.

[9] Persson PS, Ahren C, Obrant KO. Aspiration biopsy smear of testis in azoospermia. Cytological versus histological examination. Scand J Urol Nephrol 1971;5(1):22-6.

[10] Male Infertility Best Practice Policy Committee of the American Urological Association, and Then Practice Committee of the American Society for Reproductive Medicine. Report on management of obstructive azoospermia. Fertil Steril 2004;82 Suppl 1:S137-41.

[11] Srivastava A, Raghavendran M, Jain M, et al. Fineneedle aspiration cytology of the testis: can it be a single diagnostic modality in azoospermia? Urol Int 2004;73(1):23-7.

[12] Mehrotra R, Chaurasia D. Fine needle aspiration cytology of the testis as the first line diagnostic modality in azoospermia: a comparative study of cytology and histology. Cytopathology 2008;19(6):363-8.

[13] Tarlatzis BC, Bili H. Intra cytoplasmic sperm injection. Survey of world results. Ann N Y Acad Sci 2000;900:336-44.

[14] Adhikary RC. Testicular fine needle aspiration cytology in azoospermic males. Nepal Med Coll J 2009;11(2):88-91.

[15] Mahajan AD, Ali NI, Walwalker SJ, et al. The role of fine-needle aspiration cytology of the testis in the diagnostic evaluation of infertility. $\mathrm{Br} \mathrm{J}$ Urol Int 1999;84(4):485-8. 